\title{
FUNCTIONAL ABILITY, COMMUNITY REINTEGRATION AND PARTICIPATION RESTRICTION AMONG COMMUNITY- DWELLING FEMALE STROKE SURVIVORS IN IBADAN
}

\author{
Hamzat T.K. ${ }^{1}$; Olaleye O.A. ${ }^{1}$; Akinwumi O.B. ${ }^{1}$
}

ABSTRACT

BACKGROUND: Stroke is not gender-discriminatory. Yet, the subject of stroke among females has apparently not received significant attention from clinical researchers. The consequences of stroke include functional and psychosocial sequelae which may cause disability, hinder community reintegration and restrict participation. The inter-relationships among functional ability, community reintegration and participation restriction of community-dwelling, female stroke survivors in Ibadan were assessed in this descriptive study.

METHODS: Fifty-two community-dwelling female stroke survivors (mean age $=56.55 \pm 9.91$ years) were surveyed using consecutive sampling technique. Their functional ability level was measured using the Functional Independence Measure (FIM) while London Handicap Scale (LHS) was used to assess their participation restriction. Data were analyzed using Spearman Rank Correlation Coefficient (rho) and Mann-Whitney $U$ test at $p=0.05$.

RESULTS: Significantly positive correlations $(p<0.05)$ were found between functional ability and community reintegration $(r=0.54 ; p=0.01)$ as well as between participation restriction and community reintegration $(r=0.34 ; p=0.05)$. Individuals with left hemiplegia had significantly higher mean rank scores in functional ability (30.41) than those who had right hemiplegia (mean rank scores $=21.94$ ).

CONCLUSION: Functional ability which appears to be related to stroke laterality showed positive association with both community reintegration and participation restriction. This suggests that improving the functional ability of the stroke survivors may reduce participation restriction and enhance their reintegration into the community. A similar study which compares male and female stroke survivors in the same community is thus necessary.

KEYWORDS: Stroke, Functional ability, Community Reintegration, Participation Restriction

DOI: http://dx.doi.org/10.4314/ejhs.v24i1.6

\section{INTRODUCTION}

Stroke is increasingly recognized as a major public health problem for women, representing the third leading cause of death and a leading cause of disability among them(1). Women account for more than 60 percent of all stroke deaths in the United States of America and men have 16\% more chance for home discharge than women (2). The fact that women tend to live about 10 years longer than men makes the burden of stroke increasingly higher and heavier in them than in men(3). The

${ }^{1}$ Department of Physiotherapy, University of Ibadan, Nigeria

Corresponding Author: Talhatu K. Hamzat, Email: talkzat@yahoo.com;tkhamzat@ comui.edu.ng relatively high prevalence of some modifiable risk factors among females could have contributed to this observation.

Although evidence indicates that gender differences in stroke risk factors are marginal (3), the impact of stroke has been shown to be stronger in women (4). It has also been noted that women tend to fare worse than men after stroke as more women are dependent on others for self-care activities than men (5). The fact that stroke occurs later in life among women than men put them at a greater risk of functional disability and institutionalization (6). Thus, the female gender seemed to increase the risk of disability and 
handicap after stroke. This increased incidence of stroke-related functional disability among female stroke survivors is likely to affect their participation in and reintegration into the community as well as their quality of life.

It has been demonstrated that physical function and quality of life is lower among poststroke female even after correcting for age and stroke severity (7). Functional disability is an important determinant of a patient's quality of life and it correlates with health status (8). In the study by Aprile et al (9), patients with higher disability perceived that they were not able to do some daily activities not only because of physical problems but also because of emotional troubles. This is aside their significant deterioration in mental health. Given the reported magnitude of disability among female stroke survivors $(7,10,6,4)$, there is a likelihood of substantial restriction in participation and difficulty in reintegrating into the community among this group occasioned by decreased functional ability. Thus, the functional ability of female stroke survivors should be assessed in relation to their participation restriction and reintegration into the community.

A cursory look at physiotherapy attendance in our clinic by patients who have had stroke showed a significant proportion is women. Yet, there is a lack of adequate information about this subset of the population in our practice location (Ibadan, Nigeria) which may be illustrative of the less attention they receive in research activities by scientists in this part of the world. Considering the prominent role women play in a typical African family setting, it becomes imperative to study issues that concern female stroke survivors in this community. This study was therefore carried out to determine the inter-relationship among physical functioning, community reintegration and participation restriction of community-dwelling female stroke survivors in Ibadan.

\section{MATERIALS AND METHODS}

This descriptive study involved 52 female stroke survivors consecutively recruited from hospitals with physiotherapy facilities within Ibadan metropolis. To be eligible to participate in the study, stroke survivors must have suffered from stroke for at least six months before recruitment, be community-dwelling and receiving physiotherapy on out-patient basis. Stroke survivors with pre-stroke history of psychiatry disorders and long-term disabling conditions like cancer, HIV/AIDS, rheumatoid arthritis, and limb amputation were excluded from this study.

The study was approved by the University of Ibadan /University College Hospital Research Ethics Committee. Permission of the Heads of Departments of Physiotherapy and managements of the hospitals from where participants were recruited, as well as the informed consent of eligible participants were obtained after the protocol for this study had been explained them.

Clinical information about age, type of stroke and side of affectation was obtained from the patients' medical records. Functional ability was assessed using the 18-item Functional Independence Measure (FIM) developed by the Uniform Data System for Medical Rehabilitation (UDS) (11).The FIM was the preferred instrument because it was reported to be more sensitive in describing levels of functional ability and more precise in defining items than other functional rating scales. Community reintegration was assessed with the 3-part Community Integration Questionnaires (CIQ). The instrument consists of questions seeking information on integration in the home, social integration level outside the home and productivity level. The higher the score, the better the community reintegration of the individual will be (12).

The London Handicap Scale (LHS) (13) was used to measure the participation restriction (degree of handicap) of the participants. This is a six-items instrument generating a profile of handicaps on six different dimensions of mobility, physical independence, occupation, social integration, orientation and economic selfsufficiency on a scale of 0 (extreme disability) to 5 (no disability). High scores on the LHS indicate low restriction. Both the FIM and LHS were researcher-administered.

Data were analyzed using the SPSS package version 11.0. Descriptive statistics of mean, frequency and percentage were used to summarize the data. Spearman Rank Order Correlation was used to test the association between functional ability, and each of community reintegration and participation restriction of the female stroke survivors. Mann-Whitney $U$ test was used to compare functional ability, community 
reintegration and participation restriction by stroke laterality and stroke subtype.

\section{RESULTS}

Fifty-two female stroke survivors aged between 37 and 85 (mean age $=56.6 \pm 9.9$ ) years participated in this study. The socio-demographic and clinical variables of the stroke survivors are presented in Table 1.

Table 1: Demographic and Clinical Characteristics of Participants

\begin{tabular}{|l|l|l|}
\hline Variable & Number & percent \\
\hline TYPE OF STROKE: & & \\
Heamorrhagic & 11 & 21.2 \\
Ischaemic & 27 & 51.9 \\
Unspecified & 14 & 26.9 \\
\hline HANDEDNESS: & & \\
Right & 51 & 98.1 \\
Left & 1 & 1.9 \\
\hline MARITAL STATUS: & 2 & 3.8 \\
Divorced & 36 & 69.2 \\
Married & 14 & 26.9 \\
Widowed & \multicolumn{2}{|l|}{} \\
\hline SIDE AFFECTED: & 24 & 46.2 \\
Right & 28 & 53.8 \\
Left & $56.6 \pm 9.9 y e a r s$ \\
\hline AGE (Mean)
\end{tabular}

Table 2 shows the comparison of functional ability, community reintegration and participation restriction between individuals with left and right hemiplegia. Individuals with left hemiplegia had higher mean rank scores in functional ability (30.41), community reintegration (28.25) and participation restriction (28.95) compared with individuals with right hemiplegia. However, it was only the FIM score that was statistically significantly higher in the individuals with left hemiplegia. The mean time since stroke onset for the participants with right hemiplegia was 26.65 months while the mean time for those with left hemiplegia had suffered the stroke was 26.38 months.
Table 2: Comparison of Functional Ability, Community Reintegration and Participation Restriction of Participants with Right and Left Side Stroke Affectation

\begin{tabular}{|l|l|l|l|l|}
\hline \multicolumn{1}{|c|}{ Variables } & $\begin{array}{l}\text { Right } \\
\mathbf{n = 2 4}\end{array}$ & $\begin{array}{l}\text { Mean Rank } \\
\text { LEFT } \\
\mathbf{n = 2 8}\end{array}$ & $\mathrm{Z}$ & $\mathrm{P}$ \\
\hline $\begin{array}{l}\text { Functional } \\
\text { ability }\end{array}$ & 21.94 & 30.41 & -2.01 & $0.04^{*}$ \\
\hline $\begin{array}{l}\text { Community } \\
\text { reintegration }\end{array}$ & 24.26 & 28.25 & -0.90 & 0.37 \\
\hline $\begin{array}{l}\text { Participation } \\
\text { restriction }\end{array}$ & 23.65 & 28.95 & -1.32 & 0.19 \\
\hline $\begin{array}{l}\text { Time since } \\
\text { stroke }\end{array}$ & 26.65 & 26.38 & -0.06 & 0.95 \\
\hline
\end{tabular}

*Significant difference at 0.05 level

The functional ability (FIM) score was significantly and positively correlated with each of community reintegration $(\mathrm{r}=0.54 ; \mathrm{p}=0.01)$ and participation restriction $(r=0.52 ; p=0.01)$ in all the participants. The participation restriction was also significantly correlated with the community reintegration $(\mathrm{r}=0.34 ; \mathrm{p}=0.03)$ in these individuals. Age had no significant correlation with functional ability, community reintegration and participation restriction. Functional ability, community reintegration and participation restriction were not significantly different $(\mathrm{p}>$ 0.05 ) between participants with haemorrhagic and ischaemic stroke subtypes.

Table 3: Correlations among Age, Functional Ability, Community Reintegration and Participation Restriction of Participants

\begin{tabular}{|l|lc|lc|l|l|}
\hline & $\begin{array}{l}\text { Age } \\
\text { rho }\end{array}$ & p & $\begin{array}{l}\text { FA } \\
\text { rho }\end{array} \quad \mathrm{p}$ & $\begin{array}{l}\text { CR } \\
\text { rho p } \quad p\end{array}$ & $\begin{array}{l}\text { PR } \\
\text { rho p }\end{array}$ \\
\hline Age & $1.00-$ & & & & & \\
\hline FA & -0.16 & 0.27 & $1.00-$ & & \\
\hline CR & -0.26 & 0.06 & $0.54^{*}$ & 0.01 & $1.00-$ & \\
\hline PR & -0.01 & 0.97 & $0.52^{*}$ & 0.01 & $0.34^{*} 0.03$ & 1.00 \\
\hline
\end{tabular}

*Significant correlation at $\mathrm{p}<0.05, \mathrm{FA}=$ Functional Ability, $\mathrm{CR}=$ Community Reintegration, $\mathrm{PR}=$ Participation Restriction 
Table 4: Comparison of Functional Ability, Community Reintegration and Participation Restriction of Participants with Haemorrhagic and Ischaemic Stroke.

\begin{tabular}{|l|l|l|l|l|}
\hline Variables & $\begin{array}{l}\text { Haem } \\
\mathbf{n = 1 1}\end{array}$ & $\begin{array}{l}\text { Mean } \\
\text { Rank } \\
\text { Isch } \\
\mathbf{n = 2 7}\end{array}$ & $\mathbf{Z}$ & $\mathbf{P}$ \\
\hline Functional ability & 22.36 & 18.33 & -1.10 & 0.31 \\
\hline $\begin{array}{l}\text { Community } \\
\text { reintegration }\end{array}$ & 22.00 & 18.48 & -0.88 & 0.37 \\
\hline $\begin{array}{l}\text { Participation } \\
\text { restriction }\end{array}$ & 20.23 & 19.20 & -0.27 & 0.27 \\
\hline
\end{tabular}

Haem- Haemorrhagic stroke subtype

Isch - Ischaemic stroke subtype

\section{DISCUSSION}

Post-stroke issues affecting women's health appear to have received comparatively less attention from researchers investigating stroke in spite of its attendant dysfunctions. This seems to be the trend with respect to research on stroke in Nigeria. This study assessed the functional ability, community reintegration and participation restriction of community-dwelling female stroke survivors in an urban settlement-Ibadan. The female stroke survivors in this study recorded a generally low score on the Functional Independence Measure. This indicates that they had lower motor performance. This is in line with earlier reports from gender-related studies on stroke that suggested that females have worse physical function outcome than males $(1,7)$.

In the present study, the functional ability was better among individuals with left hemiplegia. This suggests that right hemiplegia is associated with lower functional ability among female stroke survivors. This may be related to their limb dominance. Given that the majority of the stroke survivors in this study have right hand dominance, the disability imposed by the stroke places a restriction on the functional use of the dominant hand. Those with left hemiplegia were found to have a higher participation and a better reintegration into the community than their counterparts with right hemiplegia. Improved participation and reintegration into the community have been associated with better rehabilitation outcomes in stroke survivors $(14,15)$.

A significant correlation was observed between functional ability and each of community reintegration and participation restriction in both the individuals with right and those with left hemiplegia. The finding in this study is similar with the findings of an earlier study where FIM score emerged as an independent predictor of restricted participation (16). Chau et al (17) and Hamzat and Peters (18) also reported an association between functional ability and level of participation. A significant correlation was also found between community reintegration and participation restriction in the participants of this study. This suggests that the more physically able a stroke survivor is, the better her reintegration and participation in the community would be. This may result in better rehabilitation outcome for the stroke survivor. It is therefore important to minimize motor impairments that lead to disability among female stroke survivors in order to limit participation restriction and enhance reintegration into the community.

Age was not correlated with functional ability, community reintegration and participation restriction in this study. Earlier studies had, however, shown a positive correlation between increasing age and disability 919, 20, 21). Age had also been associated with restriction in participation $(22,23)$. The absence of correlation in this present study may be attributable to the narrow age-range and the sample size. Differences in the present and earlier studies maybe attributed to the fact that the stroke survivors involved in the earlier studies were in their $7^{\text {th }}$ decade and above compared with the mean age of 56.6 years in this study.

No significant difference was obtained in the mean rank scores of functional ability, community reintegration and participation restriction between participants with ischaemic and haemorrhagic stroke subtypes. This may suggest that stroke subtypes have no association with each of functional ability, community reintegration and participation restriction among these communitydwelling female stroke survivors. This is contrary to the report that the type of stroke had an influence on the disability level and physical functioning of stroke survivors (24). Those researchers reported that haemorrhagic stroke 
patients showed a better rehabilitative prognosis than those with cerebral infarct. An early study reported that haemorrhagic stroke survivors showed functional gain faster than ischaemic stroke survivors (25). Nevertheless, the finding in this study is comparable with the one in an earlier study where no difference in functional recovery was found between the two stroke subtypes after a one year follow-up (26).

Female stroke survivors in this study had a generally low level of functional ability. Functioning was worse in stroke survivors with right hemiplegia but stroke subtype was not significantly correlated with the level of functional ability, community reintegration and participation restriction. Considering the known higher life expectancy advantage in women, reducing the burden of stroke in them becomes imperative. It may be necessary to compare the functional ability, community reintegration and participation restriction in male and female stroke survivors in the same community.

\section{REFERENCES}

1. 1.Petrea RE, Beiser AS, Seshadri S, KellyHayes M, Kase CS, Wolf PA. Gender Differences in Stroke Incidence and Poststroke Disability in the Framingham Heart Study. Stroke 2009; 40: 1032-37.

2. Kidwell CS, Warach S. Acute ischemic cerebrovascular syndrome: Diagnostic Criteria of Stroke2003; 34 (12): 2995-98.

3. Bousser MG. Stroke in women - The 1997 Paul Dudley White International Lecture. Circulation 1999; 99: 463-67.

4. Bolego C, Poli A, Paoletti R. Smoking and gender. Cardiovasc Res 2002; 53: 568-76.

5. Bonata B, Solomon N, Broad JB. Prevalence of stroke and stroke-related disability: estimates from the Auckland Stroke Studies. Stroke 1997; 28: 1898-902.

6. Kelly-Hayes M, Beiser A, Kase CS, Scaramucci A, D'Agostino RB,Wolf PA. The influence of gender and age on disability following ischaemic stroke. The Framingham Study. J Stroke Cerebrovasc Dis2003; 12(3): 119-26.

7. Gray LJ, Spring N, Bath PMW, et al. Sex Differences in Quality of Life in Stroke Survivors. Data From the Tinzaparin in
Acute Ischaemic Stroke Trial (TAIST). Stroke 2007; 38: 2960-64.

8. Adams RD, Victor MA. Principles of Neurology.5thed. New York, 1993.

9. 8.Aprile I, Piazzini DB, Bertolini C, et al. Predictive variables on disability and quality of life in stroke outpatients undergoing rehabilitation. NeurolSci2006; 27(1): 40-46.

10. Gladder EL, Stegmayr B, Norrving B, et al. for the Risks of Stroke Collaboration. Sex differences in management and outcome after stroke. A Swedish National Perspective. Stroke 2003; 34: 1970-75.

11. Finch E, Brooks D, Stratford P, Mayo N. Physical rehabilitation outcome measures: a guide to enhance clinical decision making.2nded. A publication of the Canadian Physiotherapy Association, 2002.

12. Willer TB, Ranhoff AH, Bautz-Holter E. Validity of questionnaire information from old people on previous cerebral stroke. Cerebrovascular Disorders 1993;4:57-58.

13. Harwood RH, Rogers A, Dickson E, Ebrahim S. Measuring handicap: the London handicap scale, a new outcome measure for chronic disease. Qual Health Care1994; 3(1): 11-16.

14. 13.Paolucci S, Antonucci G, Pratesi L, Traballesi M, Grasso MG, Lubich S. Poststroke depression and its role in rehabilitation of inpatients. Arch Phys Med Rehabil 1999; 80: 985-90.

15. 14.Gillen R, Tennen H, McKee TE, GernertDott P, Affleck G. Depressive symptoms and history of depression predict rehabilitation efficiency in stroke patients. Arch Phys Med Rehabil2001; 82:1645-49.

16. D'Alisa S, Bando S, Mauro A, Miscio G. How does stroke restrict participation in long term post-stroke survivors? Acta Neurol Scand 2005; 112(3): 157-62

17. 16.Chau JPC, Thompson DR, Twinn S, Chang AM, Woo J. Determinants of participation restriction among community dwelling stroke survivors: a path analysis. BMC Neurol 9:49

18. Hamzat TK, Peters GO. Motor function and participation among Nigerian stroke survivors: 6-month follow-up study. NeuroRehabilitation 2009; 25: 137-42

19. Nakayama H, Jorgensen HS, Raaschou HO, Olsen TS. The influence of age on stroke 
outcome: the Copenhagen Stroke Study. Stroke 1994; 25: 808-13.

20. Sanchez-Blanco I, Ochoa-Sangrador C, Lopez-Munain L, Izquierdo-Sanchez M,Fermoso-Garcia $\mathrm{J}$ Predictive model of functional independence in stroke patients admitted to a rehabilitation program. ClinRehabil1999; 13: 464-75

21. Bagg S, Pombo AP,Hopman W. Effect of age on functional outcomes after stroke rehabilitation. Stroke 2002; 33:179-85.

22. 21.Desrosiers J, Noreau L, Rochette A, Bourbonnais D, Bravo G, Bourget A. Predictors of long-term participation after stroke. Disabil Rehabil 2006; 28: 221-30.

23. Desrosiers J, Demers L, Robichaud L, Vincent C, Belleville S, Ska B. Short-term changes in and predictors of participation of older adults after stroke following acute care or rehabilitation. Neurorehabil Neural Repair 2008; 22: 288-97.

24. Paolucci S, Antonucci G, Grasso MG, et al. Functional outcome of ischaemic and haemorrhagic stroke patients after inpatient rehabilitation. A Matched Comparison. Stroke 2003; 34: 2861-65.

25. Chae J, Zorowitz RD, Johnson MV. Functional outcome of hemorrhagic and nonhemorrhagic stroke patients after inpatient rehabilitation. Am J Phys Med Rehabil 1996; 75: 177-82.

26. Franke CL, van Swieten JC, Algra A, and van Gijn J. Prognostic factors in patients with intracerebral haematoma. J Neurol Neurosurg Psychiatry 1992; 55: 653-57. 